\title{
Phylogenetic relationship among field isolates of mycoplasmas and acholeplasmas in two South Australian dairy herds based on sequencing of a short $16 S$ rRNA gene fragment
}

\author{
Abd Al-Bar Al-Farha ${ }^{1 *}$, Kiro Petrovski ${ }^{2,3,4}$, Jamie Moffat ${ }^{2}$, Mohammad Farouq Sharifpour ${ }^{2}$, Manouchehr \\ Khazandi $^{3}$, Razi Jozani ${ }^{5}$, Eman Taher ${ }^{2}$, Andrew Hoare ${ }^{6}$, and Farhid Hemmatzadeh ${ }^{2,3}$ \\ 1* Department of Animal Production, Technical Agricultural College, Northern Technical University, \\ Mosul, Iraq. 41002. Email of the corresponding author: dr.abdalbar@ntu.edu.iq \\ ${ }^{2}$ School of Animal and Veterinary Sciences, The University of Adelaide, Roseworthy, South Australia, \\ 5371, Australia \\ ${ }^{3}$ Australian Centre for Antimicrobial Resistance Ecology, The University of Adelaide, Adelaide, South \\ Australia, 5000, Australia \\ ${ }^{4}$ Davies Centre, School of Animal and Veterinary Sciences, The University of Adelaide, Roseworthy, \\ South Australia, 5371, Australia \\ ${ }^{5}$ Department of Veterinary Clinical Sciences, Tabriz University, Tabriz, 51666-14766, Iran \\ ${ }^{6}$ South East Vets, Mt Gambier, South Australia, 5290, Australia.
}

\begin{abstract}
Mycoplasma mastitis has been recognized as an emerging disease with a significant impact on the dairy industry. This study aimed to determine the genotypic distribution of some Mycoplasma and Acoleplasma spp isolated from two commercial dairy farms in South Australia based on 16S rRNA sequencing, and compare their evolutionary relationship to some similar isolates from elsewhere. Neighbour-joining phylogeny of $16 \mathrm{~S}$ rRNA demonstrated the involvement of four different spp. isolated from Farm 1 including: M. bovis, M. bovirhinis, Acholeplasma laidlawii and A. axanthum while M. alkalescens was isolated from Farm 2. Two strains of M. bovis showed similarity to Egyptian, Hungarian and Chinese strains. M. bovirhinis clustered with the Egyptian group. Mycoplasma alkalescens grouped with Swedish and Japanese strains. The Acholeplasma group showed two distinct clusters of A. laidlawii and A. axanthum. Determination of the species/genera involved in mastitis may enhance the molecular epidemiology and in-turn can contribute to controlling strategies of the disease.
\end{abstract}

Keywords: Mycoplasma, Acholeplasma, mastitis, phylogeny, 16S rRNA, cattle

\section{Introduction}

Mastitis caused by Mycoplasma spp is among the emerging challenges facing the dairy industry worldwide, resulting in significant economic consequences. Similarly to the more common mastitis pathogens, Mycoplasma mastitis can affect milk quantity and quality [1-3] More than 200 spp. of mycoplasmas, acholeplasmas and other related mollicutes have been discovered [4]. Several of these mollicutes are of great concern in the dairy industry including M. bovis, M. bovigenetalium, M. alkalescens, M. californium, and M. canadense. Other isolates that are less 
frequently involved in bovine mastitis include: M. arginini, M bovirhinis, M. leachii, and M. dispar [5]. In addition, A. laidlawii has been reported to be less significant [4] or of equal significance to mastitis cases caused by mycoplasmas $[1,6]$. Determining the species and strains involved should contribute to diagnostic and control strategies, in addition to providing a better understanding of the epidemiology of Mycoplasma mastitis in Australian dairy herds. The usefulness of 16S rRNA sequencing, due to the high copy numbers of sequenced data, has been proven and it is an efficacious, discriminatory, sensitive and accurate tool for studying the epidemiology of pathogens [7]. Copy numbers of some mollicutes have been estimated for the 16S rRNA gene to vary between 400 and 2000 [8].

Although the genotyping of Australian strains of M. bovis as the major pathogenic Mycoplasma in cattle has been reported recently [9], other mastitis causing mycoplasmas and non-pathogenic milk mollicutes are yet to be studied. Moreover, co-infection of mycoplasmas and Acholeplasma laidlawii has been recently reported to cause similar mastitis to other major mastitis pathogens [1]. This study aimed to determine the genotype distribution of Mycoplasma spp and other milk mollicutes isolated from two commercial dairy farms in South Australia, and compare their evolutionary relationship to isolates collected elsewhere.

\section{Materials and Methods}

Milk samples originated from two commercial dairy farms from the South East and Mid North regions of South Australia. A total of 368 milk samples were collected from Farm 1. Of them, one representative sample for each individual identified species was selected based on sequencing results [1]. The remaining 40 milk samples were collected from Farm 2. One sample of M. alkalescens isolated from Farm 2 was selected based on sequencing and 16S rRNA universal primer results. All samples were positive for Mycoplasma on conventional culture. Axenization of these bacteria was carried out. DNA was extracted directly from milk samples using DNA extraction kit (Qiagene, Germany). One set of universal primers included Mol-F: 5'-GGCGAAYGGGTGAGTAACAC-3' and reverse primer Mol-R: 5'CATHGYCTTGGTRRGCYNTTA-3'. We have developed HRM analysis and qPCR assays to cover the variable parts of the $16 \mathrm{~S}$ rRNA from mollicutes with the conserved primer binding sites. The PCR product is a 180 nucleotide and our submitted sequence for Acholeplasma has $>700 \mathrm{bp}$. We have amplified short part of the sequence to compare wider ranges of mollicutes; i.e., the primers and the sequences have been extracted from submitted sequences with different lengths but the assay has run on short $180 \mathrm{bp}$ sequence for test development and screening the archive. Real-time PCR-HRM analysis was performed to discriminate between some of these isolates using two pairs of genus-level universal primers targeting $16 \mathrm{~S}$ rRNA [10]. Based on their HRM profile, one representative sample from each different profile was selected for $16 \mathrm{~S}$ rRNA sequencing. Subsequently, DNA of the specific band $(b p=180)$ was purified from gel using (Qiagene, Germany) for sanger sequencing. Sanger sequencing was performed at the Australian Genome Research Facility (AGRF, Adelaide, Australia). Assembling of sequences was performed using (ClustalX, 2.1) and compared with selected closest neighbors references identified by NCBI (www.ncbi.nlm.nih.gov). Evolutionary analyses at cluster level were conducted in MEGA7 (Molecular Evolutionary Genetics Analysis, version 7.0). The evolutionary history at the cluster level was inferred using the Neighbour-Joining method [11]. The optimal tree with the sum of branch length $=1.97698025$ is shown. To build a reliable tree, huge length sequences were trimmed. The tree is drawn to scale, with branch lengths in the same 
units as those of the evolutionary distances used to infer the phylogenetic tree. The evolutionary distances were computed using the Poisson correction method and are in the units of the number of amino acid substitutions per site. All ambiguous positions were removed for each sequence pair. There were a total of 1738 positions in the final dataset. Evolutionary analyses were conducted in MEGA7 [12].

\section{Results}

In this study, six different field isolates of mycoplasmas and acholeplasmas have clustered in three distinct groups. The Acholeplasma group compromises two distinct clusters of field isolates of acholeplasmas. First, A. laidlawii (MH259813.1) showed 100\% similarity to other bovine strains of this spp. isolated in The United States and South Korea (JN935887.1, NR074448.2 and LC201977.1), and were clearly distinct from other environmental A. laidlawii (FJ226559.1, J65556.1 and JN935888) presented in Figure 1. Second, A. axanthum (MH259849.1) showed 99\% similarity to US (FJ876270.1) and Swedish (NR 028827.1) strains. Mycoplasma alkalescens (MH259845.1) was isolated from Farm 2, a 400 cow herd in the Mid North region of South Australia. The farm had a rising SCC over a period of four weeks with multiple antimicrobial treatment failures. Mycoplasma alkalescens clustered into the same clades of Swedish strain PG51 and other Japanese PG51 strains with reference number LC158831.1. The phylogenetic position of the M. bovirhinis strain in this study (MH266037.1) showed high similarity to an Egyptian strain: Fay. Bu1-10 (Fig 1). Two different strains of M. bovis has been recorded in this study, the first strain (40) clustered with M. bovis strains: 08M, Ningxia-1 and JF4278. The second field strain of M. bovis in this study (9029) was grouped with Egyptian and Hungarian strains.

\section{Discussion}

This study aimed to determine the genotypic distribution of some Mycoplasma and Acoleplasma spp isolated from two commercial dairy farms in South Australia based on 16S rRNA sequencing, and compare their evolutionary relationship to some similar isolates from elsewhere. The presence of A. laidlawii in milk samples from mastitis cows remains a controversial subject, however, with some authors considering it as pathogenic and others suggesting that it acts as an environmental milk saprophyte [1, 13-17] Acholepllasma axanthum was firstly reported in 1970 [18], and its pathogenicity in pneumonic swine has been studied [19]. A. axanthum has been isolated from mastitic milk [20, 21]. However, its role in mastitis is still unknown. The effects of some of the aforementioned mollicutes on milk quality and quantity have already been testified [1]. Co-infection with more than one species has severe consequences on milk compositions, similar to major conventional mastitis pathogens. Studying the correlation between genetic, observational and pathological effects of these genera/species may contribute in determination of their role in bovine mastitis.

Mycoplasma alkalescens (MH259845.1) was isolated from Farm 2, a 400 cow herd in the Mid North region of South Australia. The farm had a rising SCC over a period of four weeks with multiple antimicrobial treatment failures. Mycoplasma alkalescens clustered into the same clades of Swedish strain PG51 [27], and other Japanese PG51 strains with reference number LC158831.1 (unpublished). 


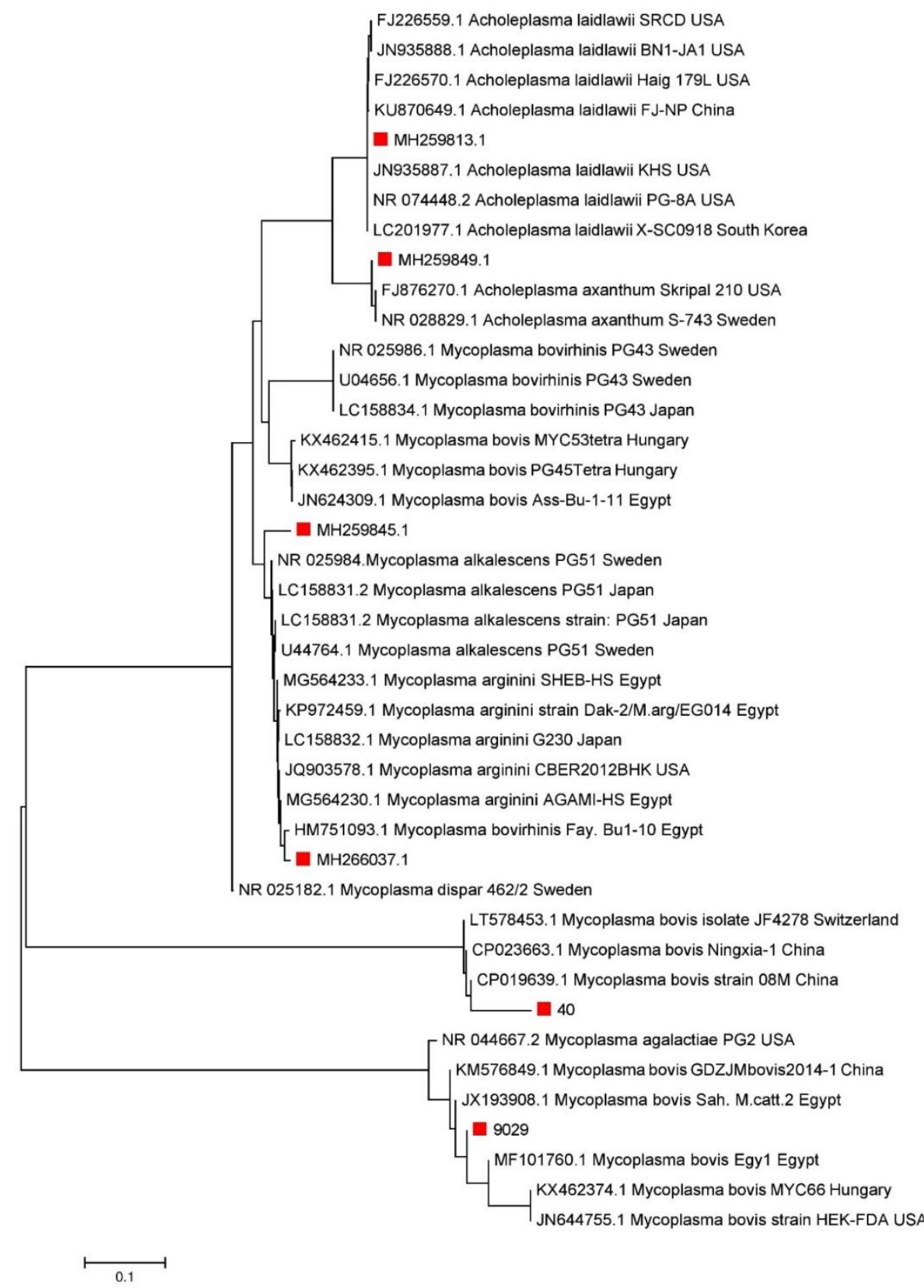

Fig. 1. Neighbor-joining consensus phylogenetic tree of six bovine milk mollicutes created by Mega 7 software based on 16S rRNA sequencing, and their relationship to referenced mollicutes. 
Mycoplasma alkalescens was firstly identified in Australian cattle in 1963 [22], and has been isolated from the nasal cavity, joints affected by arthritis, mammary gland affected by mastitis, cows with dystocia and cows with endometritis [23-25]. This reflects the ability of this pathogen for colonization in a range of tissues. Further studies on the pathogenicity of these pathogens in mastitis cases are required. The phylogenetic position of the M. bovirhinis strain in this study (MH266037.1) showed high similarity to an Egyptian strain: Fay. Bu1-10 (Fig 1). Mycoplasma bovirhinis is well known to be isolated from the respiratory organs and causes secondary infections in cattle [26]. However, this pathogen has also been isolated from cows with mastitis [1, 27]. Mycoplasma bovirhinis strain PG51 has been reported previously as a secondary invader in mastitic cows in more than $70 \%$ of Australian dairy herds, which can be explained by the ascending transmission from the nasal secretions of calves during suckling [28]. Mycoplasma bovirhinis sequences in this study clustered with the M. arginini group which may clinically explain the usual co-invasion of these genetically related mycoplasmas in bovine diseases $[1,29]$.

Two different strains of M. bovis has been recorded in this study. The first strain (40) clustered with M. bovis strains: 08M, Ningxia-1 and JF4278. The first two of these strains have been isolated in China [30, 31], while the third strain was identified in Switzerland [3]. The second field strain of M. bovis in this study (9029) was grouped with Egyptian and Hungarian strains $[32,33]$. The genetic relatedness between some of the strains isolated in this study and those previously isolated elsewhere indicate a correlation of the molecular epidemiologic distribution of mycoplasmas, and it is influenced by live animal movement interstate or foreign trade. Although the results of this study are not representative of all dairy herds in South Australia, the existing strains of pathogenic mycoplasmas may raise the awareness to include them in perspective epidemiological surveys and control strategies.

\section{References}

[1] Al-Farha A, Hemmatzadeh F, Khazandi M, Hoare A, Petrovski K: Evaluation of effects of Mycoplasma mastitis on milk composition in dairy cattle from South Australia. BMC Vet Res, 13(1), 2017. DOI:10.1186/s12917-017-1274-2

[2] Pothmann H, Spergser, J, Elmer, J, Prunner, I, Iwersen, M, Klein-Jobstl, D, Drillich, M: Severe Mycoplasma bovis outbreak in an Austrian dairy herd. J Vet Diagn Invest, 27(6):777-783, 2015. DOI: $10.1177 / 1040638715603088$

[3] Aebi M, Bodmer M, Frey J, Pilo P: Herd-specific strains of Mycoplasma bovis in outbreaks of mycoplasmal mastitis and pneumonia. Vet Microbiol. 157(3-4):363-368, 2012. DOI:10.1016/j.vetmic.2012.01.006.

[4] Nicholas R, Ayling R, McAuliffe L: Mycoplasma Diseases Of Ruminants. Wallingford: CABI; 2008.

[5] Parker A, Sheehy P, Hazelton M, Bosward K, House J. A review of mycoplasma diagnostics in cattle. J Vet Intern Med. 32(3):1241-1252, 2018. DOI:10.1111/jvim.15135

[6] Counter D: A severe outbreak of bovine mastitis assoicated with Mycoplasma bovigenitalium and Acholeplasma laidlawii. Vet Rec, 103, 130-131, 1978.

[7] Kuppeveld F, Johansson K, Galama J, Kissing J, Bolske G, Hjelm E, van der Logt J, Melchers W: $16 \mathrm{~S}$ rRNA based polymerase chain reaction compared with culture and serological methods for diagnosis of Mycoplasma pneumoniae infection. Eur J Clin Microbiol Infect, 13(5):401-405, 1994. DOI: 10.1007/bf01971997

[8] Peredeltchouk M, Wilson David S, Bhattacharya B, Volokhov D, Chizhikov V: Detection of mycoplasma contamination in cell substrates using reverse transcription-PCR assays. J Appl Microbiol,110(1):54-60, 2010. DOI:10.1111/j.1365-2672.2010.04853.x 
[9] Parker A, Shukla A, House K, Hazelton M, Bosward K, Kokotovic B, Sheehy P: Genetic characterization of Australian Mycoplasma bovis isolates through whole genome sequencing analysis. Vet Microbiol, 196:118-125, 2016. DOI:10.1016/j.vetmic.2016.10.010

[10] Al-Farha A, Petrovski K, Jozani R, Hoare A, Hemmatzadeh F: Discrimination between some Mycoplasma spp. and Acholeplasma laidlawii in bovine milk using high resolution melting curve analysis. BMC Res Notes, 11(1), 2018. DOI:10.1186/s13104-018-3223-y

[11] Saitou, N, Nei M: The neighbor-joining method: a new method for reconstructing phylogenetic trees. Mol Biol Evol, 1987. DOI:10.1093/oxfordjournals.molbev.a040454

[12] Kumar S, Stecher G, Tamura K. MEGA7: Molecular Evolutionary Genetics Analysis Version 7.0 for Bigger Datasets. Mol Biol Evol, 33(7):1870-1874, 2016. DOI:10.1093/molbev/msw054

[13] Boonyayatra S, Fox L, Gay J, Sawant A, Besser T: Discrimination between Mycoplasma and Acholeplasma species of bovine origin using digitonin disc diffusion assay, nisin disc diffusion assay, and conventional polymerase chain reaction. J Vet Diagn Invest, 24(1):7-13, 2011. DOI: $10.1177 / 1040638711425936$

[14] Counter D, A severe outbreak of bovine mastitis assoicated with Mycoplasma bovigenitalium and Acholeplasma laidlawii. Vet Rec, 103, 130-131. 1978

[15] KIRK, J. H., GLENN, K., RUIZ, L. \& SMITH, E: Epidemiologic analysis of Mycoplasma spp isolated from bulk-tank milk samples obtained from dairy herds that were members of a milk cooperative. J Am Vet Med Assoc, 211, 1036-8, 1997.

[16] Seffner W, Pfutzner H, Wehnert C: [Mycoplasma mastitis of cattle. 11. Histological udder findings after experimental infection with Mycoplasma bovigenitalium and Acholeplasma laidlawii]. Arch Exp Veterinarmed, 37, 375-382, 1983.

[17] Singh A, Gupta P, Banga H: Pathogenicity of Acholeplasma laidlawii for the goat udder. Aust Vet J, 67(4):155-156, 1990. DOI:10.1111/j.1751-0813.1990.tb07743.x

[18] Tully J, Razin S: Acholeplasma axanthum, sp. n.: a new sterol-nonrequiring member of the Mycoplasmatales. J Bacteriol, 103, 751-754, 1970.

[19] Stipkovits L, Romváry J, Nagy Z, Bodon L, Varga L: Studies on the pathogenicity of Acholeplasma axanthum in swine. J Hyg, 72(2): 289-296, 1974. DOI:10.1017/s0022172400023500

[20] González R, Wilson D: Mycoplasmal mastitis in dairy herds. Vet Clin N Am-Food A,19(1):199-221, 2003. DOI:10.1016/s0749-0720(02)00076-2

[21] Roy J, Francoz D, Labrecque O: Mastitis in a 7-week old calf caused by Mycoplasma bovigenitalium. Vet J, 176(3):403-404, 2008. DOI:10.1016/j.tvj1.2007.04.006

[22] Hudson J, Etheridge J: A new type of pleuropneumonia-like organisms (PPLO) from the nose of cattle. Aust Vet J. 39(1):1-5, 1963. DOI:10.1111/j.1751-0813.1963.tb04166.x

[23] Ghanem M, Higuchi H, Tezuka E, Ito H, Devkota B, Izaike Y, Osawa T: Mycoplasma infection in the uterus of early postpartum dairy cows and its relation to dystocia and endometritis. Theriogenology, 79(1): 180-185, 2013. DOI: 10.1016/j.theriogenology.2012.09.027

[24] Manso-Silvan L, Tardy F, Baranowski E, Barre A, Blanchard A, Breton M, Couture C, Citti C, Dordet-Frisoni E, Dupuy V, Gaurivaud P, Jacob D, Lemaitre C, Nikolski M, Nouvel L, Poumarat F, Thebault P, Theil S, Thiaucourt F, Sirand-Pugnet P: Draft genome sequences of Mycoplasma alkalescens, Mycoplasma arginini, and Mycoplasma bovigenitalium, three species with equivocal pathogenic status for cattle. Genome Announc, 1(3), 2013. DOI:10.1128/genomea.00348-13

[25] Sosa C, Tirante L, Chaves J, Pol M, Ambrogi A, Giraudo J, Tamiozzo P: [Identification of species of Mycoplasma and Ureaplasma diversum from Argentinian dairy herds]. Rev Argent Microbiol, 50(1):31-35, 2018. DOI:10.1016/j.ram.2017.02.010

[26] Hata E, Nagai K, Murakami K: Complete genome sequence of Mycoplasma bovirhinis Strain HAZ141_2 from bovine nasal discharge in Japan. Genome Announc, 5(39). 2017. DOI:10.1128/genomea.01000-17

[27] Pettersson B, Leitner T, Ronaghi M, Bölske G, Uhlen M, Johansson K: Phylogeny of the Mycoplasma mycoides cluster as determined by sequence analysis of the 16S rRNA genes from the two rRNA operons. J Bacteriol, 178(14):4131-4142, 1996. DOI:10.1128/jb.178.14.4131-4142. 
[28] Hirose K, Kawasaki Y, Kotani K, Tanaka A, Abiko K, Ogawa H: Detection of Mycoplasma in mastitic milk by PCR analysis and culture method. J Vet Med Sci, 63(6):691-693, 2001. DOI:10.1292/jvms.63.691

[29] Szacawa E, Niemczuk K, Dudek K, Bednarek D, Rosales R, Ayling R: Mycoplasma bovis infections and co-infections with other Mycoplasma spp. with different clinical manifestations in affected cattle herds in eastern region of Poland. B Vet I Pulawy, 59(3):331-338, 2015. DOI:10.1515/bvip-20150049

[30] Sun P, Luo H, Zhang X, Xu J, Guo Y, He S: Whole-genome sequence of Mycoplasma bovis strain Ningxia-1. Genome Announc, 6(4). 2018. DOI:10.1128/genomea.01367-17

[31] Chen S, Hao H, Zhao P, Gao P, He Y, Ji W, Wang Z, Lu Z, Liu Y, Chu Y: Complete genome sequence of Mycoplasma bovis strain 08M. Genome Announc, 5(19), 2017. DOI:10.1128/genomea.00324-17

[32] Sahar E, Metwally A, Al-Saud, N, Ibrahim, M: Molecular typing of different isolates of Mycoplasma bovis, Proceedings of the 6th Scientific Conference of Animal Wealth Research in the Middle East and North Africa, Hurghada, Egypt, 27-30 September 2013. Massive Conferences and Trade Fairs, pp. 277-290.

[33] Sulyok K, Kreizinger Z, Wehmann E, Lysnyansky I, Bányai K, Marton S, Jerzsele Á, Rónai Z, Turcsányi I, Makrai L, Jánosi S, Nagy S, Gyuranecz M: Mutations associated with decreased susceptibility to seven antimicrobial families in field and laboratory-derived Mycoplasma bovis strains. Antimicrob Agents Ch, 2016. DOI: 10.1128/aac.01983-16: AAC.01983-16. 